\title{
USING VISION SYSTEM TECHNOLOGIES TO ENABLE OPERATIONAL IMPROVEMENTS FOR LOW VISIBILITY APPROACH AND LANDING OPERATIONS
}

\author{
Lynda J. Kramer, Kyle K. E. Ellis, Randall E. Bailey, Steven P. Williams, Kurt Severance, \\ Lisa R. Le Vie and James R. Comstock \\ NASA Langley Research Center, Hampton, VA
}

\begin{abstract}
Flight deck-based vision systems, such as Synthetic and Enhanced Vision System (SEVS) technologies, have the potential to provide additional margins of safety for aircrew performance and enable the implementation of operational improvements for low visibility surface, arrival, and departure operations in the terminal environment with equivalent efficiency to visual operations. To achieve this potential, research is required for effective technology development and implementation based upon human factors design and regulatory guidance. This research supports the introduction and use of Synthetic Vision Systems and Enhanced Flight Vision Systems (SVS/EFVS) as advanced cockpit vision technologies in Next Generation Air Transportation System (NextGen) operations.
\end{abstract}

Twelve air transport-rated crews participated in a motion-base simulation experiment to evaluate the use of SVS/EFVS in NextGen low visibility approach and landing operations. Three monochromatic, collimated head-up display (HUD) concepts (conventional HUD, SVS HUD, and EFVS HUD) and two color head-down primary flight display (PFD) concepts (conventional PFD, SVS PFD) were evaluated in a simulated NextGen Chicago O'Hare terminal environment. Additionally, the instrument approach type (no offset, 3 degree offset, 15 degree offset) was experimentally varied to test the efficacy of the HUD concepts for offset approach operations.

The data showed that touchdown landing performance were excellent regardless of SEVS concept or type of offset instrument approach being flown. Subjective assessments of mental workload and situation awareness indicated that making offset approaches in low visibility conditions with an EFVS HUD or SVS HUD may be feasible.

\section{Introduction}

The U.S. air transportation system is undergoing a transformation to accommodate the movement of large numbers of people and goods in a safe, efficient, and reliable manner [1]. One of the key capabilities envisioned to achieve this Next Generation Air Transportation System (NextGen) is the concept of equivalent visual operations (EVO). EVO is the capability to achieve the safety of current-day Visual Flight Rules (VFR) operations and maintain the operational tempos of VFR irrespective of the weather and visibility conditions.

One research challenge for EVO is the definition of required equipage on the aircraft and at the airport. With today's equipment and regulations, significant investment is required in on-board equipment for navigation, surveillance, and flight control and on the airport for precision guidance systems and approach lighting systems for "all-weather" landing capability [2]. The levels of equipment redundancy, capability, maintenance, performance and crew training dramatically increase as landing visibility minima decrease. Synthetic Vision Systems and Enhanced Flight Vision Systems (SVS/EFVS) offer a means of providing EVO capability without significant airport infrastructure investment while potentially increasing efficiency and throughput during low visibility operations.

NASA Langley Research Center (NASA LaRC) is conducting research to ensure effective technology development and implementation of regulatory and design guidance to support introduction and use of SVS/EFVS advanced cockpit vision technologies in NextGen operations.

\section{Background}

SVS is a computer-generated image of the external scene topography, generated using aircraft attitude, high-precision navigation, and data of the 
terrain, obstacles, cultural features, and other required flight information. EFVS is an electronic means to provide a display (typically on a head-up display, or HUD) of the external scene by use of an imaging sensor, such as a Forward-Looking InfraRed (FLIR) or millimeter wave radar. Both SVS and EFVS are "vision-based" technologies intended to create, supplement, or enhance the natural vision of the pilot.

NASA and others have developed and shown that SVS technologies provide significant improvements in terrain awareness and reductions for the potential of Controlled-Flight-Into-Terrain incidents/accidents [34], improvements in Flight Technical Error to meet Required Navigation Performance criteria [5], and improvements in Situation Awareness (SA) without increased workload [6-8]. As such, SVS, often displayed on a Head-Down Display (HDD), is emerging as standard equipage for Part 23 and Part 25 flight decks even though, to date, no "operational credit" is obtained from equipage [9].

EFVS capability on a HUD using FLIR sensor technology has garnered a significant share of the business aircraft market and is growing in Part 121 and 135 operations [10]. EFVS provides many of the same operational benefits as SVS technology, but it uses a real-time view of the external environment, independent of the aircraft navigation solution or database. These differences, in part, enable operational credit by use of an approved EFVS. In 2004, Title 14 of the Code of Federal Regulations (CFR) Section (§) 91.175 was amended to enable operators conducting straight-in instrument approach procedures (in other than Category II or Category III operations) to descend below the published Decision Altitude (DA), Decision Height (DH) or Minimum Descent Altitude (MDA) down to 100 feet (ft) above the touchdown zone elevation (TDZE) using an approved EFVS in lieu of natural vision. (To descend below 100 feet above the TDZE, the required visual references for landing must be distinctly visible and identifiable by the pilot using natural vision.) An approved EFVS must meet the requirements of $\S 91.175(\mathrm{~m})$ and the use of a HUD or an equivalent display is essential.

Synthetic and Enhanced Vision Systems (SEVS) technologies, such as SVS/EFVS in combination with HDD/HUD, form the basis for an electronic display of visual flight references (terrain, obstacles, and operations-critical navigational and situational references) on electronic cockpit display(s) for the flight crew. Integrating these SEVS displays with conformal symbology provides important situation, guidance, and/or command information as necessary and/or appropriate to enable all weather approach and landing operations. The primary reference for maneuvering the airplane is based on what the pilot sees through the SEVS, in lieu of or supplemental to the pilot's natural vision, in low visibility conditions.

The key concept for 14 CFR $\S 91.175$ is that an EFVS can be used in lieu of natural vision from the $\mathrm{DA} / \mathrm{DH} / \mathrm{MDA}$ to $100 \mathrm{ft}$ height above the TDZE provided the visibility of the enhanced vision image meets or exceeds the published visibility required for the approach being flown and the required visual references are clearly identified. Minimum aviation system performance standards for EFVS are now available in RTCA DO-315 [11]. RTCA DO-315 also provides performance standards for SVS but without operational credit.

The FAA has started a rulemaking project to expand operational credit for EFVS beyond what is currently authorized under 14 CFR §91.175 [12]. RTCA DO-315A [13] was drafted to establish performance standards in concert with this rulemaking project; that is, EFVS operations through the approach to touchdown in visibility as low as $1000 \mathrm{ft}$ runway visual range (RVR) by sole use of an approved EFVS in lieu of natural vision. Past NASA research [14] supports the viability of this expanded EFVS operational credit where it was shown that using an EFVS to hand-fly approaches through touchdown resulted in excellent localizer tracking performance and an improvement in glideslope tracking performance.

Unlike EFVS, the possible path for SVS operational credit is not through revision of 14 CFR $\S 91.175$, but is based on FAA Order 8400.13 ("Procedures for the Evaluation and Approval of Facilities for Special Authorization Category I Operations and All Category II and III Operations”; i.e., "SA CAT I" approaches). Specifically, RTCA DO-315B establishes performance standards for SVS enabling lower than standard Category I minima or a reduction in the required minimum visibility. These performance standards for SVS operational credit do not require the use of a HUD.

The emerging challenge for NextGen - and the subject of NASA research - is to develop performance-based standards for SEVS technologies 
that create EVO and beyond. During 2010-11, NASA and the FAA jointly conducted an integrated ground simulation and flight testing activity (NextGen SEVS) to evaluate the use of SVS/EFVS in NextGen low visibility surface, takeoff/departure, and approach/landing operations, especially as these technologies, in isolation or integrated with Automatic Dependent Surveillance-Broadcast (ADS-B) information, may impact flight crew(s) workload, head-down time, and ability to detect potential collisions with objects, obstacles or other traffic. Results from the NextGen SEVS fixed-base ground simulation [15] and flight testing activity [16] indicated that:

- Expanding the portion of the visual segment in which EFVS can be used in lieu of natural vision appears to be viable in visibilities as low as 1000 feet RVR as touchdown performance was acceptable without any apparent workload penalties (both in simulation and flight test results).

- A lower DH of 150 feet and/or possibly reduced visibility minima using SVS appears to be viable when implemented on a head-up display (based on simulation results) or head-down display (based on flight test results).

This motion-based simulation experiment was a follow-on study to evaluate items uncovered by the NextGen SEVS testing and data analysis. Specifically, this paper describes an experimental evaluation of HUD SEVS concepts, instrument approach offsets, HUD edge lines positioning sources, and guidance cue variations on landing performance and subjective ratings of situation awareness and workload during terminal area operations. The objective data from this test are being used to develop performance-based approach and landing standards which might establish a basis for future all-weather landing certification.

\section{Method}

\section{Subjects}

Twenty-four pilots served as test subjects for the research, representing twelve flight crews. Ten crews flew for major U.S. air carriers and two crews flew for a major cargo carrier. Crews were paired by airline to ensure crew coordination and cohesion with regard to operating procedures. All test subjects were male. The Captains' average age was 55.7 years and the First Officers' average age was 49.4 years. The Captains had an average of over 14,782 flight hours with 20 years of commercial flying. The First Officers had an average of over 9,459 flight hours with 12 years of commercial experience. The Captains were recruited on the basis of HUD experience (at least 100 hours), with preference given to pilots with Enhanced Vision (EV)/EFVS experience. All pilots were required to hold an Airline Transport Pilot rating.

The Captain was the designated pilot-flying (PF) throughout all the trials and the First Officer served as the pilot-monitoring (PM).

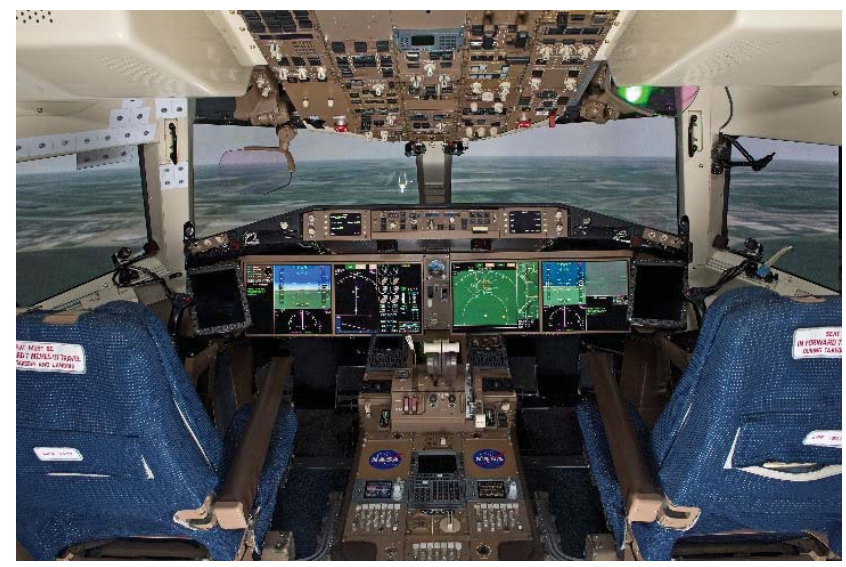

Figure 1. Research Flight Deck Simulator with HUD and Head-down Instrument Panel

\section{Simulation Facility}

This research was conducted in the Research Flight Deck (RFD) simulator at NASA LaRC (Figure 1). The RFD is configured with four 10.5-inch Vertical (V) by 13.25-inch Horizontal (H), 1280x1024 pixel resolution color displays, tiled across the instrument panel. Also, the RFD includes a HUD on the left side of the cab, Mode Control Panel, and Flight Management System (FMS). Two 5-camera Smart Eye $^{\mathrm{TM}}$ head and eye tracking systems are installed to quantify both crew member's head movement and eye-gaze behavior. Both eye tracking systems data outputs and the simulator state data output are timesynchronized.

The full-mission RFD simulates a Boeing B-757200 aircraft, albeit controlled through sidestick inceptors.

A collimated out the window (OTW) scene is produced by an Evans and Sutherland Image Generator graphics system providing approximately $200^{\circ} \mathrm{H}$ by $40^{\circ} \mathrm{V}$ field-of-view (FOV) at 26 pixels per degree. 
The sidestick inceptor force gradients and deflection characteristics mimic the Airbus A-320 aircraft [17]. A rate-command attitude hold (RCAH) fly-by-wire (FBW) control law, coded in Matlab/Simulink, was installed for this test. The pilot and co-pilot inceptors are directly linked as if mechanically connected.

The auto-throttle system backdrives the throttle handles to directly reflect the power setting commanded to the engines. Take-off, go-around (TOGA) buttons and autothrottle disconnect buttons are placed on the throttle handles.

\section{Simulator Database}

Operations were simulated at Chicago O'Hare International Airport (FAA identifier: KORD). The simulation was built around FAA source data for KORD, valid from 11 March 2010 to 8 April 2010. These data were used to develop all flight plans, scenarios, approach paths, and OTW, synthetic vision (SV) and EV databases.

Day simulations were flown, with the weather tailored to create the desired visibility conditions.

Testing included an experimental variation of instrument approaches, with and without an offset. Testing without offsets was conducted on KORD Runways 9R, 4R, 22L, and 22R. Testing with offsets was conducted on Runway 27L.

Straight-in (no offset) approaches were flown to runways with Medium intensity Approach Lighting System with Runway (MALSR) alignment indicator lights installed. Testing included an experimental variation of touchdown zone and centerline (TDZ/CL) lights (on and off), where operations with TDZ/CL lights were conducted on Runway 9R; otherwise, Runways 4R, 22L, or 22R were used. Offset approaches were flown to Runway 27L with Approach Lighting System with Sequenced Flashing Lights (ALSF-2) installed. All runways included high intensity runway lights and serviceable centerline and surface markings. Airport lighting was drawn using calligraphics.

\section{Audio Effects}

Altitude call-outs were played over the flight deck speakers. The automatic altitude calls-out started at "500 feet" (i.e., $500 \mathrm{ft}$ above the TDZE). The "approaching minimums" and "minimums" call-outs were at $100 \mathrm{ft}$ above and at the DA/DH.
Flare "prompts" in the form of additional altitude call-outs were used on all runs (" 100 ," " 50 ," “40," " 30 ," " 20, , and " 10 " at the corresponding radar altitudes in feet).

\section{Head-Down Displays}

Figure 1 shows the simulator's four main instrument panel displays: a) PF left display, including primary flight display (PFD); b) PF right display including navigation display (ND); c) PM left display, including ND; and, d) PM right display, including PFD. The format and content of these displays were varied experimentally.

\section{Head-Up Display}

The RFD is equipped with a Rockwell-Collins HGS-6700 HUD. The HUD is collimated and subtends approximately $40^{\circ} \mathrm{H}$ by $30^{\circ} \mathrm{V}$ FOV. However, a reduced FOV $\left(26^{\circ}\right.$ by $\left.21^{\circ}\right)$ was simulated to be directly comparable to the previous fixed-base NextGen SEVS simulation study. The video input to the HUD was either a SV or EV source (Figure 2). The symbology format was a modified version of the HGS Primary mode format. The symbology included a runway outline (edge lines), a flight path angle reference cue and a flight path-referenced guidance cue. The guidance cue was driven by the B-757 flight director. Radar altitude was shown digitally underneath the altitude scale when below $2500 \mathrm{ft}$ above ground level (AGL) and also underneath the flight path marker when below $500 \mathrm{ft}$ AGL. In addition, a HUD flare cue, consisting of a flare "prompt," was provided where, at $50 \mathrm{ft}$ AFL, two "plus" signs flashed above the flight path marker. 


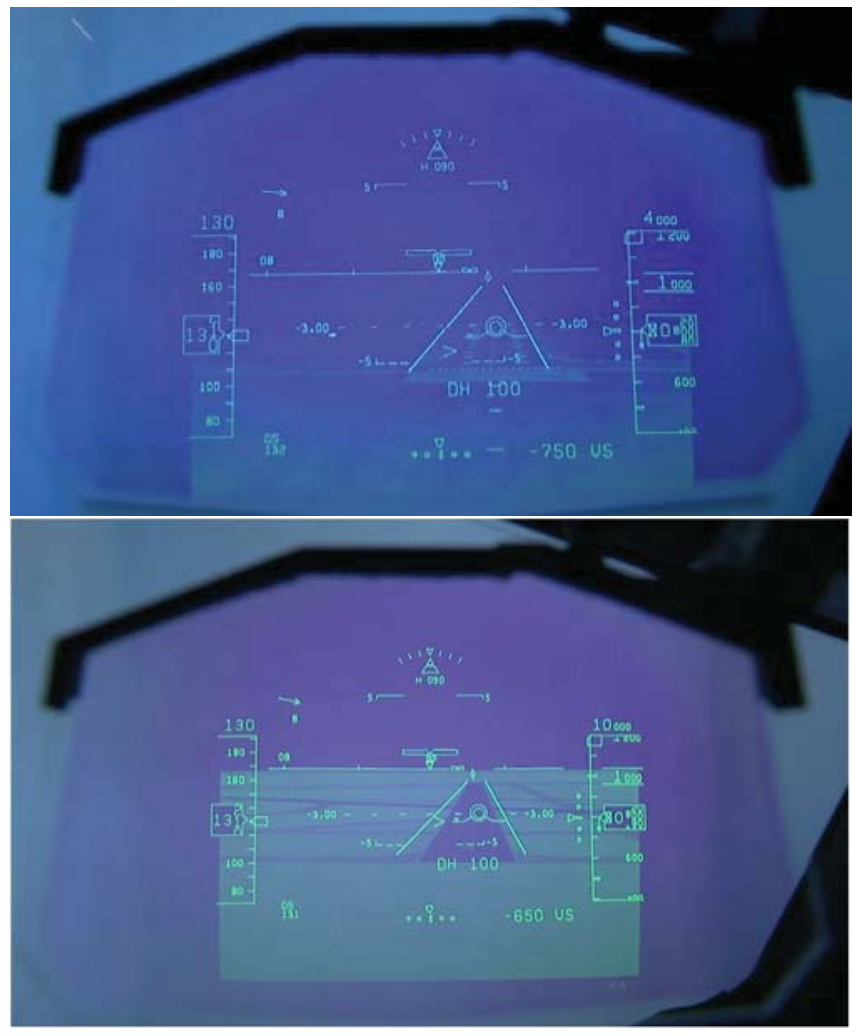

Figure 2. EFVS HUD (top view) and SVS HUD (bottom view) Symbology Format

The PF had controls to adjust the symbology brightness and the imagery brightness and contrast. The PF also had a declutter control, implemented as a four-button castle switch on the pilot's sidestick. The four "declutter" states available to the PF were: 1) Declutter All (no symbology or imagery); 2) Symbology Toggle on/off; 3) Imagery Toggle on/off; and 4) Display All (both symbology and imagery).

The HUD was stowed when not being used to avoid any confounding from the HUD being in place during “non-HUD” runs.

\section{SV Simulations}

A SV database was developed generally following the standards from DO-315B [18]. The database used a 1 arc-second digital elevation model of a $110.25 \mathrm{~nm}$ (East-West) by 145.6 (North-South) $\mathrm{nm}$ area centered around KORD. The elevation model was draped with an elevation-based coloration texturing.

Each KORD runway was modeled as an asphaltcolored polygon using the threshold data and runway widths. Threshold lines, edge lines, and runway numbers were added.
The intended landing runway was denoted on the display concept being evaluated, either as a conformal magenta outline on the head-down PFD depiction, or an $8000 \mathrm{x} 200 \mathrm{ft}$ outline (shown as edge lines) on the HUD.

The SVS-PFD symbology mirrored the HUD using conformal depictions for the flight path marker, single cue flight path-referenced guidance symbology, and flight path angle reference cue.

Several SV-specific items are called out to note:

- When drawn on the HUD, the SV database terrain texturing and coloration was slightly changed to improve its visual perception primarily for conversion into a gray-scale format.

- The SV depiction was always drawn in a headingup format. Any crosswind was evident by conformal lateral positioning of the flight path marker. However, the flight path marker and guidance cue were limited and displayed as ghosted representations if their conformal positions exceeded pre-determined values.

\section{EV Simulation}

The EV real-time simulation is created by the Evans and Sutherland EPX physics-based sensor simulation. The ORD database was instantiated with material code properties. From this database, an IR sensor simulation, interacting with this material-coded database and the simulated weather conditions, created the desired test experimental conditions.

The EV simulation mimicked the performance of a short-wave/mid-wave FLIR, using a $\sim 1.0$ to 5.0 micron wavelength detector. The nominal enhanced visibility was approximately $2400 \mathrm{ft}$.

The EV eye point reference was placed $5 \mathrm{ft}$ below the pilot design eye reference point, but otherwise properly boresighted with the aircraft. In the B-757, the pilot is approximately $20 \mathrm{ft}$ above the ground during surface operations. This EV eye point reference/parallax error generates $2.5 \mathrm{mrad}$ error to a point located $2000 \mathrm{ft}$ away - approximately half of the accuracy budget of the EFVS per current DO-315 accuracy requirements [18].

\section{Navigational Performance Variations}

Variations in navigational accuracy were simulated on each run, bounding $\pm 12 \mathrm{ft}$ vertical and $\pm 12 \mathrm{ft}$ horizontal deviations from the true position. 
These values were determined by using actual measured WAAS Performance data found in the Global Positioning System WAAS Performance Standard document [19]. This effect was added for realism in positioning system accuracy. The selected inaccuracies were randomly varied across each subject's test matrix and were held constant during a run.

\section{Independent Variable - Crew Display Concepts}

Two head-down flight display concepts and three head-up flight display concepts were evaluated.

\section{Head-Down Flight Display Concepts}

The two HDD concepts (referred to as the Conventional PFD and SVS PFD) are shown in Figure 3 , differing from each other only in the absence or presence of SVS on the PFD. The HUD was stowed during HDD evaluations.
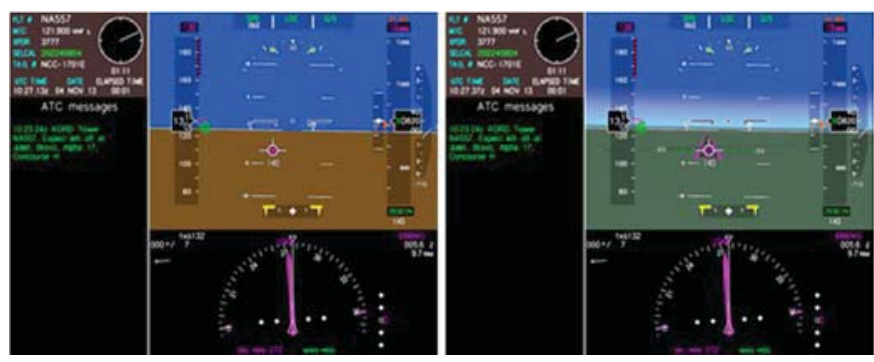

Figure 3. Conventional PFD (left view) and SVS PFD (right view)

The SVS PFD (on the PF left display) portrayed a $33^{\circ} \mathrm{V} \mathrm{x} 44^{\circ} \mathrm{H}$ field-of-regard. Assuming a 25 inch distance from the Design Eye Reference Point to the display, the SVS concept had a minification factor of approximately 2.1. The PF left display also had a datalink message area and Horizontal Situation Indicator (HSI). The PM right display (Figure 4) showed a quad-view of flight information: a PFD (upper left); HSI (lower left); datalink message area (lower right); and, a FLIR repeater or blank area (blank during baseline and SVS HDD evaluations; upper right).

The PF (right display) and PM (left display) NDs always showed flight traffic and navigational information in the airborne mode (Figure 4). The PF and PM NDs transitioned to a moving map mode when on the ground and groundspeed less than 80 knots (not shown). The PM ND included a runway inset view in both airborne and moving map modes. (The presence and absence of airborne and surface traffic were experimentally evaluated, but the results are not reported here.)

\section{Head-Up Flight Display Concepts}

The three HUD concepts (referred to as the Conventional HUD, SVS HUD and EFVS HUD) were tested, differing from each other only in the absence or presence and type of imagery (SV or FLIR) on the PF HUD.

The Conventional PFD (i.e., no SVS) concept was displayed during these runs. The PM (head-down) right display showed FLIR imagery in the upper right of the quad-view for EFVS HUD runs and was blank (black in color) for Conventional and SVS HUD runs. In Figure 2, the EFVS and SVS HUD display concepts are shown.

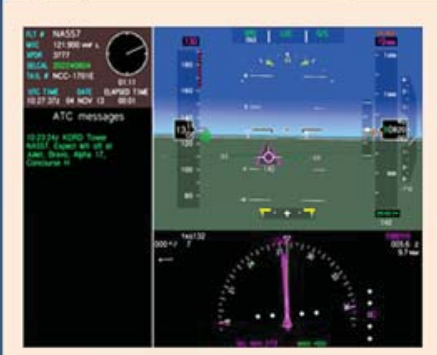

PF Left Display

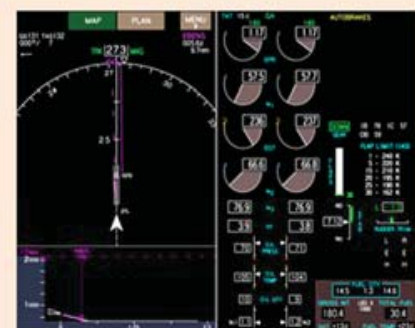

PF Right Display

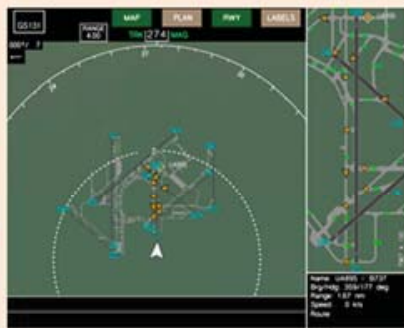

PM Left Display

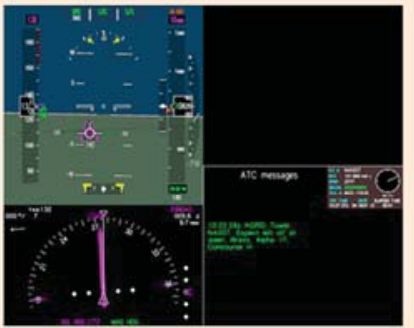

PM Right Display

Figure 4. PF and PM Head-Down Displays

\section{Independent Variable - Visibility Level}

Four OTW visibility levels, $1000 \mathrm{ft}, 1200 \mathrm{ft}, 1400$ $\mathrm{ft}$, and $1800 \mathrm{ft}$ RVR, were tested in combination with the SEVS display concepts.

\section{Independent Variable - Instrument Approach Procedure Offset}

The instrument approach procedure (IAP) offset was varied between 0-deg (no offset), 3-deg, and 15deg. Each IAP used a 3-degree descent angle. These 
offsets are all within that allowable under straight-in instrument approach procedures.

The 0-deg offset approach used a $150 \mathrm{ft}$ DA flying to one of 4 ORD runways $(4 \mathrm{R}, 9 \mathrm{R}, 22 \mathrm{R}$, or 22L). The approach started 3 nautical miles (nm) from the runway threshold. The weather consisted of low to moderate winds with either 10 knot headwind, 10 knot tailwind, 7.5 knot crosswind, or 15 knot crosswind, light turbulence (root-mean-square (rms) of $1 \mathrm{ft} / \mathrm{sec}$ ), and varying OTW visibility levels (1800 ft, $1400 \mathrm{ft}$, or $1000 \mathrm{ft}$ RVR).

The 3-deg offset approach was an ILS approach with a 3 deg localizer offset to the right of the runway heading and $200 \mathrm{ft}$ DA to Runway 27L. The approach started approximately $5.1 \mathrm{nmi}$ from the runway threshold. The weather consisted of either a 7.5 knot left or right crosswind (varied by run) with light turbulence and a fixed OTW visibility of 1400 RVR.

The 15-deg offset approach was a simulated LDA (localizer-type directional aid) approach with a 15 deg localizer offset and $320 \mathrm{ft}$ DA to Runway 27L. The approach started approximately $5.1 \mathrm{nmi}$ from the runway threshold. The weather consisted of a $10 \mathrm{knot}$ headwind with light turbulence. A fixed OTW visibility of 4000 RVR was used for the 15-deg offset so that crews had sufficient visibility to continue beyond the DA (320 ft) using natural vision.

\section{Independent Variable - Edge Lines Positioning Source on Offset Instrument Approach}

The HUD edge lines positioning source was experimentally varied while flying an IAP with an offset (ILS 3-degree offset approach and the LDA 15deg offset approach). In one case, the edge lines were positioned by the navaid source; thus, the edge lines do not overlay the runway of intended landing, but are aligned with the offset localizer. In the other case, the edge lines are geo-referenced to the landing runway.

The motivation for testing this independent variable arose since there is not an industry standard for HUD edge lines positioning sources. Manufacturers use both types. The experiment assessed if there was any influence when using different HUD concepts and edge lines positioning sources on the decision to land and on performance.

\section{Independent Variable - HUD Guidance Cue Variation on Offset Instrument Approach}

The guidance cue was experimentally varied while flying an IAP with a 3-deg offset. The guidance was either removed at $\mathrm{DA} / \mathrm{DH}$ or not removed, in which case, the guidance cue would latch to the flare cue during landing.

There is no industry standard for removal of the guidance cue on the HUD. This experiment design tested two extreme conditions. The motivation was to assess if there were any effect from a guidance cue that may be directing the flight toward a point 3-deg offset from the landing runway.

\section{Evaluation Task}

The PF hand-flew the approach from the left seat with the auto-throttle set to "speed-hold" at the approach speed of 130 knots indicated airspeed. The auto-throttle automatically reduced to idle thrust at 35 $\mathrm{ft}$ above ground level (AGL) for landing. The run was terminated once the PF completed the landing, roll-out and turn-off or upon go-around initiation. The aircraft was configured to land prior to each run (landing gear down and flaps 30 degrees).

The PFs were instructed to fly the aircraft as if there were passengers aboard, track the approach path, and land within the touchdown zone with an acceptable sink rate. After landing, they were to maintain the centerline and exit at the expected taxiway at a speed of 5 to 15 knots at the 90 degree exits or 30 knots at the high-speed exits. They were also instructed to initiate a go-around if the approach became unstable or if there were any safety concerns.

\section{Crew Procedures}

The PF flew the approach using the HUD or HDD as the primary flight reference. The PM monitored using the available HDD information, including a FLIR repeater (when EFVS HUD was flown), and the OTW scene and assisted the PF as appropriate and necessary. There was no transfer of control from the PF to PM (or vice versa). The crew procedures were standardized and trained.

\section{Baseline and SVS Procedures}

The procedures for the baseline (i.e., no SVS or EFVS installed) and SVS configurations were identical and followed normal crew instrument approach procedures. One of the intended functions of the SVS is to improve the pilot's ability to conduct the 
instrument portion of the approach - not to enable descent below the published DA/DH. Training emphasized that the crews follow $\$ 91.175$ procedures that the required visual references to continue the approach below the published DA/DH and for landing must be distinctly visible and identifiable by the pilot using natural vision.

\section{EFVS Procedures}

The EFVS procedures were built around common practice in current EFVS operations and FAA requirements (14 CFR §91.175 (l)) but extended to emphasize that to descend below the $\mathrm{DA} / \mathrm{DH}$ and to descend below $100 \mathrm{ft}$ height above the TDZE depended upon the PF being able to recognize and identify the required visual references, using EFVS.

\section{Experiment Matrix}

The baseline 0 -deg offset experiment test matrix (Table 1) was created from four visibility conditions against five SEVS configurations (combinations of vision systems and displays) as crews flew no offset IAPs. The test matrix also included 3-deg and 15-deg offset approaches (Table 2) flown while using a HUD with variations in Vision System (None, SVS, EFVS), Edge Lines Positioning Source (georef, navaid), and Guidance Cue (remove at DA, retain and latch to flare cue).

Wind variations were balanced across the experiment matrix for each crew/pilot to evenly distribute the conditions across the configurations. Thus, wind effects were tested but not in a 'within subjects' variation. It was assumed that left and right crosswinds could be interchanged without affecting any experimental results.

Table 1. Experiment Matrix for No Offset Approaches

\begin{tabular}{|c|c|c|c|c|c|}
\hline \multirow{2}{*}{ Display } & \multirow{2}{*}{$\begin{array}{c}\text { Vision } \\
\text { System }\end{array}$} & \multicolumn{4}{|c|}{ OTW Visibility (ft) } \\
\cline { 3 - 6 } & $\mathbf{1 8 0 0}$ & $\mathbf{1 4 0 0}$ & $\mathbf{1 2 0 0}$ & $\mathbf{1 0 0 0}$ \\
\hline \multirow{3}{*}{ HUD } & None & & $\mathrm{X}$ & & \\
\cline { 2 - 6 } & SVS & & $\mathrm{X}$ & $\mathrm{X}$ & $\mathrm{X}$ \\
\cline { 2 - 6 } & EFVS & & $\mathrm{X}$ & $\mathrm{X}$ & $\mathrm{X}$ \\
\hline \multirow{3}{*}{ HDD } & None & $*_{\mathrm{X}}$ & $\mathrm{X}$ & & \\
\cline { 2 - 6 } & $\mathrm{SVS}$ & $\mathrm{X}$ & $\mathrm{X}$ & & \\
\hline
\end{tabular}

* $200 \mathrm{ft}$ DA; All others $150 \mathrm{ft}$ DA
Table 2. Experiment Matrix for Offset Approaches

\begin{tabular}{|c|c|c|c|c|}
\hline $\begin{array}{c}\text { HUD } \\
\text { Vision } \\
\text { System }\end{array}$ & $\begin{array}{c}\text { Edge } \\
\text { Lines } \\
\text { Source }\end{array}$ & $\begin{array}{c}\text { Guidance } \\
\text { Variation }\end{array}$ & $\begin{array}{c}\text { 3-deg } \\
\text { Offset } \\
\text { ILS }\end{array}$ & $\begin{array}{c}\text { 15-deg } \\
\text { Offset } \\
\text { LDA }\end{array}$ \\
\hline SVS & Georef & latch to flare cue & $\mathrm{X}$ & $\mathrm{X}$ \\
\hline EFVS & Navaid & $\begin{array}{c}\text { latch to flare } \\
\text { cue }\end{array}$ & $\mathrm{X}$ & $\mathrm{X}$ \\
\hline EFVS & Georef & $\begin{array}{c}\text { latch to flare } \\
\text { cue }\end{array}$ & $\mathrm{X}$ & $\mathrm{X}$ \\
\hline None & Georef & $\begin{array}{c}\text { latch to flare } \\
\text { cue }\end{array}$ & $\mathrm{X}$ & $\mathrm{X}$ \\
\hline SVS & Georef & remove at DA & $\mathrm{X}$ & \\
\hline EFVS & Navaid & remove at DA & $\mathrm{X}$ & \\
\hline None & Navaid & remove at DA & $\mathrm{X}$ & \\
\hline EFVS & Georef & remove at DA & $\mathrm{X}$ & \\
\hline None & Georef & $\begin{array}{c}\text { remove at DA } \\
\mathrm{X}\end{array}$ \\
\hline
\end{tabular}

\section{Measures}

During each approach and landing run, path error, pilot control inputs, and touchdown performance (sink rate and speed at touchdown, longitudinal and lateral landing distance) were measured for analysis.

After each run, pilots completed the AFFTC Workload Estimate Scale [20] and the 10-point Situational Awareness Rating Technique [21]. After data collection was completed, pilots provided rank orders on which crew display concepts (Conventional HDD, SVS HDD, Conventional HUD, SVS HUD, EFVS HUD) they preferred to fly with in lowvisibility conditions. Through a semi-structured interview, the pilots also responded to a post-test questionnaire to elicit comments on operational benefits/detriments observed with regard to 1) runway edge lines being driven by a navaid reference or georeferenced to the runway on an offset instrument approach and 2) guidance cue removal variations on an offset instrument approach.

\section{Test Conduct}

The subjects were given a one-hour briefing describing the experiment, HUD and HDD concepts, crew procedures, and evaluation tasks. The test purpose was described to the test subjects as 
"evaluating the potential use of EFVS and SVS for reduced landing weather minima."

After the briefing, a 1.5 hour training session in the RFD was conducted to familiarize the subjects with the aircraft handling qualities, display symbologies, pilot procedures, and controls. In particular, in-simulator training highlighted the crew procedures for EFVS and SVS operations and landing performance. The training emphasized that they must always remain safe and if they felt unsafe conditions exist, the necessary precautions, including a goaround, should be executed immediately.

Since none of the pilots were familiar with the handling characteristics of the RFD simulator (a sidestick-equipped B-757), each PF was trained to an acceptable standard of performance.

Table 3. Touchdown Performance Scorecard

\begin{tabular}{|c|c|c|c|}
\hline $\begin{array}{c}\text { Performance } \\
\text { Value }\end{array}$ & Desired & Adequate & $\begin{array}{c}\text { Not } \\
\text { Adequate }\end{array}$ \\
\hline $\begin{array}{l}\text { Lateral } \\
\text { Distance from } \\
\text { Centerline }\end{array}$ & $\begin{array}{c}\text { Within +/- } \\
27 \mathrm{ft}\end{array}$ & $\begin{array}{c}\text { Between +27 } \\
\text { and +58 ft or } \\
\text { Between -27 } \\
\text { and -58 ft }\end{array}$ & $>+/-58 \mathrm{ft}$ \\
\hline $\begin{array}{l}\text { Longitudinal } \\
\text { Distance from } \\
\text { Threshold }\end{array}$ & $\begin{array}{c}\text { Between } \\
750 \text { to } 2250 \\
\mathrm{ft}\end{array}$ & $\begin{array}{l}\text { Between } 200 \& \\
750 \mathrm{ft} \text { or } \\
\text { Between } 2250 \\
\& 2700 \mathrm{ft}\end{array}$ & $\begin{array}{l}<200 \text { or } \\
>2700 \mathrm{ft}\end{array}$ \\
\hline Sink rate & $\begin{array}{l}\text { Between } 0 \\
\text { to } 6 \mathrm{ft} / \mathrm{sec}\end{array}$ & $\begin{array}{c}\text { Between } 6 \text { to } \\
10 \mathrm{ft} / \mathrm{sec}\end{array}$ & $>10 \mathrm{ft} / \mathrm{sec}$ \\
\hline Airspeed (kts) & $\begin{array}{c}\text { Between } \\
\mathrm{V}_{\text {ref }}-5 \text { to } \\
\mathrm{V}_{\text {ref }}+5\end{array}$ & $\begin{array}{l}\text { Between } V_{\text {ref }}-5 \\
\text { to } V_{\text {ref }}-15\end{array}$ & $\begin{array}{c}<\mathrm{V}_{\text {ref-15 }}-15 \\
\quad \text { or } \\
>\mathrm{V}_{\text {ref }}+5\end{array}$ \\
\hline
\end{tabular}

Note: Vref +5 is the approach speed

In Table 3, touchdown performance criteria are shown. These criteria were developed by using existing FAA AC120-28D [22, Appendix 3] and JAR AWO [23] performance-based "auto-land" standards for touchdown (T/D) longitudinal position, lateral position from centerline, and sink rate.

After each training run, a landing performance "scorecard" against these criteria was displayed for feedback. The pilots were asked to meet the desired performance criteria. Training concluded once the pilots demonstrated repeatable desired landing performance, albeit with an occasional adequate performance score.

Data collection lasted approximately 8.5 hours and was followed by debriefings which included a final questionnaire. The entire session including lunch and breaks lasted approximately 1.5 days.

\section{Results}

A repeated measures design was used for this experiment in which multiple measurements (dependent variables) were made on the same subject (pilot) under different experimental conditions (factors). Linear Mixed Models (LMMs) - statistical models for continuous dependent measures in which the residuals are normally distributed but may not be independent or have constant (homogeneous) variance [24] - were applied in the analysis.

The within-subject fixed factors for this experiment were SEVS display concept, visibility level, approach offset, HUD edge-line positioning source, and guidance cue removal variation. The random factor was crew.

For this paper, the dependent variables evaluated for landing performance were touchdown longitudinal position (in $\mathrm{ft}$ ), touchdown lateral position (in $\mathrm{ft}$ ), and touchdown sink rate (in $\mathrm{ft} / \mathrm{sec}$, or fps). Subjective ratings of workload and situation awareness were also measured for both the PF and PM on each run.

Touchdown statistics were used to evaluate how effectively the pilots could land with the different SEVS display concepts. In addition, the number of landings and the number of go-arounds for the various combinations of fixed factors are provided. These data were provided in tabular form. Note that for touchdown lateral position data in these tables, the "min" value equates to the maximum deviation to the left of centerline and the "max" value equates to the maximum deviation to the right of centerline.

Separate LMM analyses were conducted on the landing performance measures, workload ratings, and SART ratings for the fixed factors of HUD SEVS concept (Conventional HUD, SVS HUD, and EFVS HUD) and approach offset (0, 3, 15 degree) and their interaction. Separate LMMs were also used to analyze touchdown performance measures, workload ratings, and SART ratings for the fixed factors of HUD Vision System (None, EFVS), HUD edge lines position source (navaid, georef) and guidance cue variation (remove at DA, retain and latch to flare cue) and their second order interactions while flying an ILS approach with a 3-deg offset. 
By-subject variance due to individual differences was accounted for by using a Random Intercept Model in the LMM analyses. Unless otherwise specified, all LMMs 1) employed the Identity (constant variance and independent residuals) covariance structure for the residuals, 2) were estimated with restricted maximum likelihood, and 3) met the assumptions of normality and constant variance for the residuals and for the random effects. If data was transformed to meet an LMM assumption, the transformation is described in the corresponding section for that analysis and any means reported are from the untransformed data.

\section{HUD SEVS Concept and Offset Approach Effects}

For the HUD SEVS Concepts in this analysis, edge lines were geo-referenced to the runway and the guidance cue was retained and latched to the flare cue during landing operations. The visibility levels were 1400 RVR for the 0-deg and 3-deg offset approaches and 4000 RVR for the 15-deg offset approaches.

\section{Touchdown Statistics}

In Table 4, the touchdown (T/D) statistics (mean, standard deviation, minimum value, and maximum value) are shown, broken out by offset approach type, for the HUD SEVS concepts flown.

Table 4. HUD SEVS Concepts Statistics for Offset Approach Type

\begin{tabular}{|c|c|c|c|c|c|c|c|c|c|c|}
\hline & & \multicolumn{3}{|c|}{ 0-deg Offset } & \multicolumn{3}{|c|}{ 3-deg Offset } & \multicolumn{3}{|c|}{ 15-deg Offset } \\
\hline & & $\begin{array}{l}\text { Conv. } \\
\text { HUD }\end{array}$ & $\begin{array}{l}\text { SVS } \\
\text { HUD }\end{array}$ & $\begin{array}{l}\text { EFVS } \\
\text { HUD }\end{array}$ & $\begin{array}{l}\text { Conv. } \\
\text { HUD }\end{array}$ & $\begin{array}{l}\text { SVS } \\
\text { HUD } \\
\end{array}$ & $\begin{array}{l}\text { EFVS } \\
\text { HUD } \\
\end{array}$ & $\begin{array}{l}\text { Conv. } \\
\text { HUD }\end{array}$ & $\begin{array}{l}\text { SVS } \\
\text { HUD }\end{array}$ & $\begin{array}{l}\text { EFVS } \\
\text { HUD }\end{array}$ \\
\hline \multicolumn{2}{|c|}{ \# TOGA \# Runs } & $1 / 12$ & $1 / 12$ & $0 / 12$ & $2 / 12$ & $1 / 12$ & $0 / 12$ & $0 / 12$ & $0 / 12$ & $0 / 12$ \\
\hline \multirow{5}{*}{ 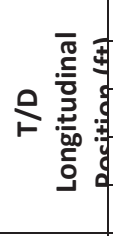 } & Mean & 1200.1 & 1400.7 & 1310.6 & 1244.6 & 1161.9 & 1179.0 & 1306.0 & 1189.4 & 1384.9 \\
\hline & Std Dev & 436.7 & 392.4 & 403.9 & 278.2 & 453.8 & 292.6 & 322.1 & 438.5 & 512.3 \\
\hline & Min & 675.7 & 618.1 & 836.7 & 853.4 & 420.2 & 649.3 & 674.9 & 591.8 & 758.2 \\
\hline & Max & 1932.4 & 1980.6 & 1923.6 & 1688.4 & 2103.8 & 1814.3 & 1686.9 & 1981.2 & 2090.5 \\
\hline & Rating & Desired & Desired & Desired & Desired & Desired & Desired & Desired & Desired & Desired \\
\hline \multirow{5}{*}{ 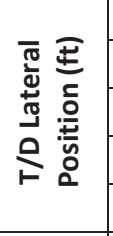 } & Mean & -1.2 & 11.7 & 8.7 & -1.6 & -4.0 & -5.5 & 0.1 & 1.2 & -2.7 \\
\hline & Std Dev & 8.6 & 6.5 & 8.3 & 9.0 & 7.4 & 4.7 & 4.8 & 4.8 & 3.4 \\
\hline & Min & -21.1 & -1.0 & -1.7 & -11.6 & -18.2 & -11.6 & -6.9 & -6.1 & -8.8 \\
\hline & Max & 7.2 & 20.9 & 21.3 & 19.8 & 5.5 & 2.6 & 9.7 & 8.7 & 1.7 \\
\hline & Rating & Desired & Desired & Desired & Desired & Desired & Desired & Desired & Desired & Desired \\
\hline \multirow{5}{*}{ 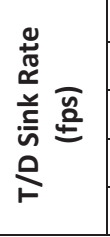 } & Mean & -4.1 & -3.2 & -3.0 & -5.0 & -4.1 & -5.4 & -3.0 & -4.0 & -3.4 \\
\hline & Std Dev & 2.2 & 1.9 & 1.4 & 2.3 & 1.9 & 1.9 & 1.1 & 2.5 & 1.3 \\
\hline & Min & -8.5 & -6.7 & -5.4 & -10.2 & -7.1 & -9.7 & -4.8 & -9.1 & -5.3 \\
\hline & Max & -1.4 & -0.7 & -0.9 & -1.8 & -1.4 & -3.2 & -1.3 & -1.5 & -0.6 \\
\hline & Rating & Desired & Desired & Desired & Desired & Desired & Desired & Desired & Desired & Desired \\
\hline
\end{tabular}

All T/D measures (lateral position, longitudinal position and sink rate) for all three HUD SEVS concepts were on average within the "Desired" landing performance criteria (Table 3) for approaches, with and without offsets.

Go-arounds were only performed while flying in the $1400 \mathrm{ft}$ visibility level and did not appear to be affected by offset approach type as they exhibited similar go-around percentages (6\% for 0 -deg offset and $8 \%$ for 3-deg offset).

\section{Touchdown Position}

Separate LMM analyses revealed no significant differences $(\mathrm{p}>0.05)$ for either $\mathrm{T} / \mathrm{D}$ longitudinal distance past threshold (mean=1256 ft, standard deviation, $\sigma=394 \mathrm{ft}$ ) or lateral position from centerline (mean=0.74 ft, $\sigma=8.4 \mathrm{ft}$ ) for HUD SEVS concept, offset approach type, or their interaction.

Figure 5 shows the T/D position while flying the HUD SEVS concepts to instrument approaches, with and without an offset. In this figure, the blue, dashed 
lines indicate the "autoland" longitudinal T/D criteria and the red, dashed lines indicate the "autoland" lateral T/D criteria.

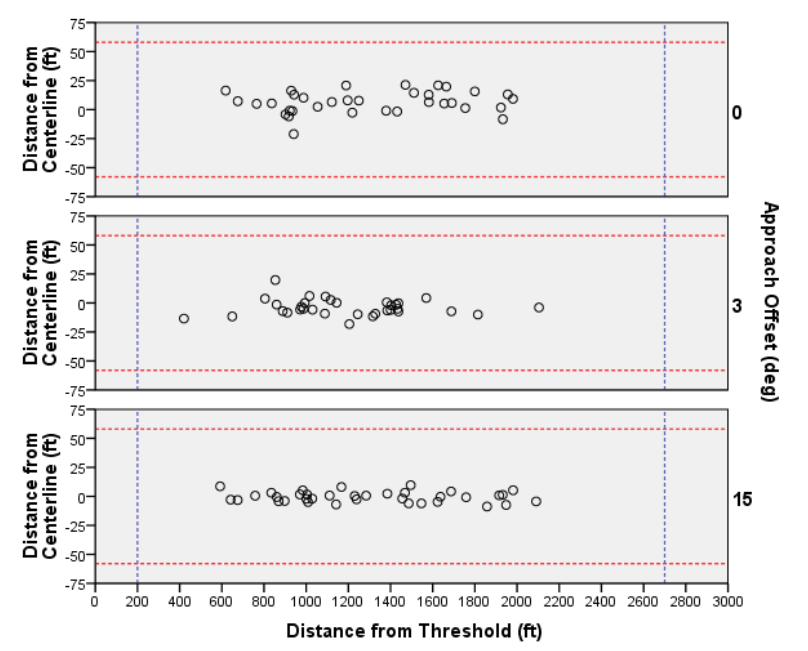

Figure 5. Landings by Approach Offset Type

Visual inspection of the data in Figure 5 showed that all HUD concepts tested in motion, regardless of offset approach type (0, 3, 15 deg) or HUD SEVS imagery type (none, SVS, EFVS), were within the JAR lateral and longitudinal touchdown criteria footprint.

\section{Touchdown Sink Rate}

A square root transformation was applied to the sink rate data to account for a negative skew in the data. A LMM analysis using this square root transformed data revealed that offset approach type was significant $(\mathrm{F}(2,66.8)=8.377, \quad \mathrm{p}=0.001)$ for touchdown sink rate (mean=-3.3 fps for the 0 and 15 deg offset approaches and mean=-4.7 fps for $3 \mathrm{deg}$ offset approaches). Operationally, these differences were inconsequential as all were within the "Desired" T/D sink rate criteria. No significant differences ( $>0.05$ ) for T/D sink rate were found for HUD SEVS concept or the interaction between HUD SEVS concept and offset approach type.

\section{Workload and Situation Awareness Ratings}

Separate LMM analyses revealed there were no significant $(\mathrm{p}>0.05)$ PF workload rating (mean $=2.4$, $\sigma=0.9$ ) differences or PF SART rating (mean $=34$, $\sigma=8)$ differences for HUD SEVS concept, offset approach type, or their interaction. There were also no significant ( $\mathrm{p}>0.05)$ PM workload ratings (mean=2.1, $\sigma=0.7$ ) or PM SART rating (mean=34, $\sigma=7$ ) differences for these two main factors or their interaction.

Both crew members rated their workload as being 'light activity, minimum demands' while flying either an EFVS HUD or SVS HUD on an instrument approach with an offset in low visibility conditions.

\section{Offset Approach on Landing Performance Discussion}

While flying with a HUD, all landings were made within the 757 autoland-defined touchdown criteria footprint (laterally within $\pm 58 \mathrm{ft}$ of centerline; longitudinally between 200 to $2700 \mathrm{ft}$ from threshold) regardless if 1) the approach being flown had an offset or not; or, 2) the HUD had vision system (EFVS or SVS) imagery or not (i.e., Conventional HUD). All but one (Conventional HUD on a 3-deg offset approach) of the HUD landings met the autoland sink rate criteria of less than $10 \mathrm{fps}$. The need to go-around appeared to be affected by visibility level (7\% in 1400 RVR vs $0 \%$ in 4000 RVR) and not HUD SEVS concept or offset approach type being flown.

Statistically equivalent crew ratings of workload and SA while flying a Conventional HUD, SVS HUD, or EFVS HUD on an instrument approach (with or without an offset), appears to indicate there were no workload or SA penalties associated with 1) adding SVS or EFVS imagery to a HUD; or, 2) flying a HUD (conventional, SVS, or EFVS) on an approach with an offset as large as $15 \mathrm{deg}$.

To date, differences in approach performance have not been analyzed, but these data indicate that the pilots were able to successfully execute the offsets up to 15 deg (straight-in IAPs) without a workload penalty and with equivalent SA while achieving statistically identical landing performance. This work suggests that an offset approach may not be a significant influence in approach and landing performance. One note in these data is the possible confound of the visibility condition at the 15 degree offset. $4000 \mathrm{ft}$ RVR was simulated at this offset because the $1400 \mathrm{ft}$ RVR visibility level (used for the no offset and 3 degree offset) was not sufficient for the crews to continue beyond the DA (320 ft) using natural vision. 


\section{Effects of Edge Lines Positioning and Guidance Cue Variation}

\section{Touchdown Statistics}

In Table 5, the T/D statistics (mean, standard deviation, minimum value, and maximum value) are shown, broken out by edge line positioning source and guidance cue variation, for the HUD SEVS concepts. The T/D measures means were used to determine which touchdown performance rating level (Desired, Adequate, or Not Adequate) as defined in Table 3 was achieved. Also provided in Table 5 are the number of runs that resulted in a go-around and the total number of runs for the HUD SEVS concepts tested.

Table 5. SEVS Concepts Statistics for HUD Edge Lines Positioning Source and Guidance Cue Variation

\begin{tabular}{|c|c|c|c|c|c|c|c|c|c|}
\hline & & \multicolumn{4}{|c|}{ Remove Guidance Cue at DA } & \multicolumn{4}{|c|}{ Latch Guidance Cue to Flare Cue } \\
\hline & & \multicolumn{2}{|c|}{$\begin{array}{l}\text { Geographically- } \\
\text { referenced Edge } \\
\text { Lines } \\
\end{array}$} & \multicolumn{2}{|c|}{$\begin{array}{c}\text { Navaid-referenced } \\
\text { Edge Lines }\end{array}$} & \multicolumn{2}{|c|}{$\begin{array}{l}\text { Geographically- } \\
\text { referenced Edge } \\
\text { Lines }\end{array}$} & \multicolumn{2}{|c|}{$\begin{array}{l}\text { Navaid-referenced } \\
\text { Edge Lines }\end{array}$} \\
\hline & & $\begin{array}{c}\text { EFVS } \\
\text { HUD }\end{array}$ & $\begin{array}{l}\text { Conv. } \\
\text { HUD }\end{array}$ & $\begin{array}{c}\text { EFVS } \\
\text { HUD }\end{array}$ & $\begin{array}{l}\text { Conv. } \\
\text { HUD }\end{array}$ & $\begin{array}{l}\text { EFVS } \\
\text { HUD } \\
\end{array}$ & $\begin{array}{l}\text { Conv. } \\
\text { HUD }\end{array}$ & $\begin{array}{l}\text { EFVS } \\
\text { HUD }\end{array}$ & $\begin{array}{l}\text { Conv. } \\
\text { HUD }\end{array}$ \\
\hline \multicolumn{2}{|c|}{ \# TOGA / \# Runs } & $0 / 12$ & $0 / 12$ & $0 / 12$ & $0 / 12$ & $0 / 12$ & $2 / 12$ & $1 / 12$ & $1 / 12$ \\
\hline \multirow{5}{*}{ 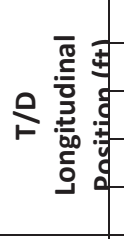 } & Mean & 1344.3 & 1155.3 & 1447.8 & 1339.0 & 1179.0 & 1244.6 & 1326.6 & 1062.8 \\
\hline & Std Dev & 286.5 & 234.5 & 679.6 & 306.8 & 292.6 & 278.2 & 890.2 & 354.5 \\
\hline & Min & 925.5 & 840.8 & 431.0 & 910.4 & 649.2 & 853.4 & 402.0 & 251.2 \\
\hline & Max & 1949.7 & 1485.2 & 2769.5 & 1928.9 & 1814.3 & 1688.4 & 3585.9 & 1516.0 \\
\hline & Rating & Desired & Desired & Desired & Desired & Desired & Desired & Desired & Desired \\
\hline \multirow{5}{*}{ 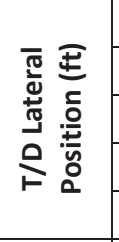 } & Mean & 3.3 & 7.8 & 4.0 & 2.1 & -5.5 & -1.6 & -7.1 & -3.5 \\
\hline & Std Dev & 8.4 & 11.9 & 8.9 & 9.8 & 4.7 & 9.0 & 5.7 & 7.4 \\
\hline & Min & -17.4 & -9.4 & -13.5 & -18.4 & -11.6 & -11.6 & -15.1 & -17.4 \\
\hline & Max & 15.3 & 39.0 & 20.9 & 21.3 & 2.6 & 19.8 & 5.0 & 8.2 \\
\hline & Rating & Desired & Desired & Desired & Desired & Desired & Desired & Desired & Desired \\
\hline \multirow{5}{*}{ 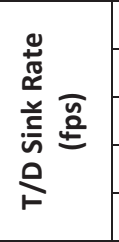 } & Mean & -4.9 & -4.4 & -3.8 & -3.5 & -5.4 & -5.0 & -5.6 & -4.5 \\
\hline & Std Dev & 2.3 & 2.4 & 2.3 & 2.0 & 1.9 & 2.3 & 2.9 & 1.3 \\
\hline & Min & -10.4 & -8.5 & -9.7 & -8.1 & -9.7 & -10.2 & -12.1 & -6.4 \\
\hline & Max & -2.5 & -1.2 & -1.6 & -0.8 & -3.2 & -1.8 & -3.3 & -2.4 \\
\hline & Rating & Desired & Desired & Desired & Desired & Desired & Desired & Desired & Desired \\
\hline
\end{tabular}

The data show that, on average, the EFVS and Conventional HUD concepts were all within the "Desired" landing performance criteria for each combination of HUD edge lines positioning source and guidance cue variation while flying an ILS approach with a 3-deg offset. Go-arounds appear to be affected by the guidance cue variation with a $0 \%$ missed approach rate for the 'remove at DA' runs and a $8 \%$ missed approach rate for the 'latch to flare cue' runs.

\section{Touchdown Position}

A Diagonal (heterogeneous variances and independent residuals) Covariate Structure was used for the T/D longitudinal distance past threshold LMM analysis. One landing whose longitudinal distance past threshold was $3586 \mathrm{ft}$ was excluded from this analysis since it was approximately 5 standard deviations $(1 \sigma=465 \mathrm{ft})$ away from the overall mean longitudinal position (1264 ft). This landing occurred during one 3deg offset run, with the HUD edge lines positioned by the navaid.

Various transformations were applied to the data to try to account for the large skew caused by this data point, but none of the transformations were able to meet the normality assumption of the residuals. As such, this landing was not used in the LMM analysis for T/D longitudinal position. Although not included in the statistical analysis because it is way outside the statistical norm, the significance of this run should not be minimized - the pilot landed outside the touchdown zone (i.e., not within first $3000 \mathrm{ft}$ of the runway) while 
flying a 3-deg offset approach with HUD edge lines positioned by the navaid.

On a 3-deg offset ILS approach, guidance cue variation $(F(1,50.39)=8.107, \quad p=0.006)$ and the interaction between guidance cue variation and edge lines positioning source $(\mathrm{F}(1,54.11)=4.772, \mathrm{p}=0.033)$ were significant for $\mathrm{T} / \mathrm{D}$ longitudinal distance past threshold. The 'remove at DA' runs averaged $1335 \mathrm{ft}$ and the 'latch to flare cue' runs averaged $1142 \mathrm{ft}$ past the threshold. Figure 6 graphically shows the interaction between guidance cue variation and edge line positioning source for T/D longitudinal position after flying a 3-deg ILS approach. When the HUD edge lines align with the landing runway, the guidance cue variation did not significantly $(\mathrm{p}>0.05)$ affect T/D longitudinal position (mean distance $=1229 \mathrm{ft}$ ). However, when the edge lines were aligned with the localizer, the guidance cue variation was significant $(F(1,39.51)=7.667, p=0.009)$ for this measure, with the 'remove at DA' runs averaging $1419 \mathrm{ft}$ and the 'latch to flare cue' runs averaging $1077 \mathrm{ft}$ past the threshold. HUD SEVS concept and the remaining second order interactions were not significant $(p>0.05)$ for this measure.

On a 3-deg offset ILS approach, guidance cue variation $(\mathrm{F}(1,50.39)=32.25, \mathrm{p}<0.001)$ was significant for T/D lateral distance from centerline, with the 'remove at DA' runs averaging $4.3 \mathrm{ft}$ left of centerline and the 'latch to flare cue' runs averaging $4.4 \mathrm{ft}$ right of centerline. Operationally, these differences are inconsequential. HUD SEVS concept, edge line positioning source, and all the remaining second order interactions were not significant $(p>0.05)$ for this measure.

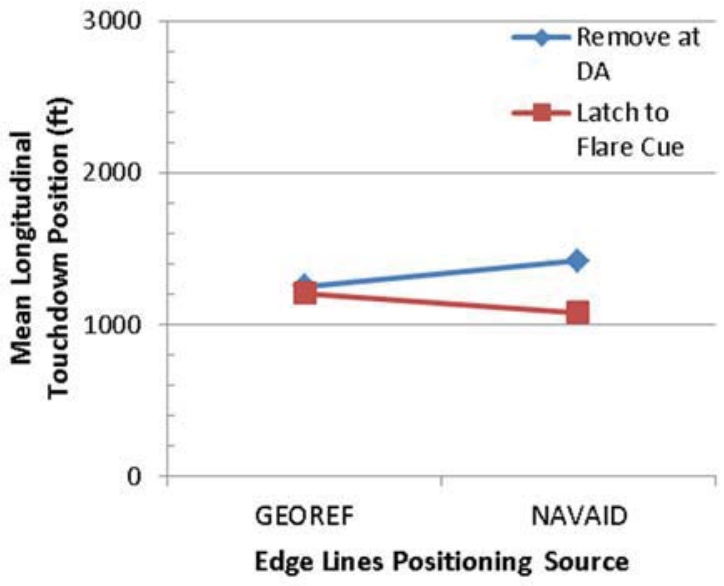

\section{Figure 6. Mean Longitudinal Distance by Guidance Cue Variation and Edge Lines Positioning Source}

\section{Touchdown Sink Rate}

Guidance cue variation $(F(1,74.05)=6.553$, $\mathrm{p}=0.013$ ) was significant for $\mathrm{T} / \mathrm{D}$ sink rate, with 'remove at DA' runs averaging $-4.1 \mathrm{fps}$ and 'latch to flare cue' runs averaging -5.1 fps. These differences are operationally inconsequential. HUD SEVS concept, edge line positioning source and all of the second order interactions were not significant $(p>0.05)$ for this measure.

\section{Workload and Situation Awareness Ratings}

Separate LMM analyses revealed there were no significant $(\mathrm{p}>0.05)$ PF workload rating (mean=2.6, $\sigma=1.0$ ) differences or PF SART rating (mean $=33$, $\sigma=8.1$ ) differences for HUD SEVS concept, guidance cue variation, edge lines positioning source, or their second order interactions. There were also no significant ( $\mathrm{p}>0.05)$ PM workload ratings (mean=2.3, $\sigma=0.7$ ) or PM SART rating (mean=34, $\sigma=6.4$ ) differences for these three main factors or their interactions.

Both crew members rated their workload as being 'light activity, minimum demands' while flying either an EFVS HUD or Conventional HUD on an instrument approach with a 3-deg offset in low visibility conditions.

\section{Edge Lines Positioning and Guidance Cue Variation Discussion}

Guidance cue variation (remove at DA, latch to flare cue) affected all three touchdown performance parameters, including the missed approach rate, while 
flying an ILS 3-deg offset approach. T/D longitudinal position past threshold was closer to the aim point with a higher (on average) T/D sink rate when the guidance cue was latched to the flare cue compared to when it was removed. The T/D lateral distance from centerline and sink rate differences due to guidance cue variation were operationally inconsequential. The percentage of missed approaches when the guidance cue was removed at DA compared to when it was latched to the flare cue was $0 \%$ and $8 \%$, respectively. There were no PF or PM workload or situation awareness rating differences due to HUD vision system concepts (EFVS, Conventional), edge lines positioning source (georef, navaid) or guidance cue variation (remove at DA, latch to flare cue).

The approach data has not been analyzed to date so the effect of the guidance cue variation below $\mathrm{DA} / \mathrm{DH}$ is uncertain.

Although the T/D, workload, and SA data shows few operationally significant differences, the pilot post-test briefing comments suggest some clear effects.

All 12 PFs stated they preferred the georeferenced positioned edge lines over navaid positioned during an offset approach. The EPs expressed that navaid positioned edge lines should never be used as they 'gave you a false sense of reality,' or were 'very confusing and very dangerous,' or 'misleading and definitely a safety concern.' Some operational benefits cited by the pilots were that the geo-referenced edge lines:

- $\quad$ led to a more stable approach as you got a mental model of the offset maneuver

- $\quad$ allowed you to plan the turn toward the runway and create a more stable approach.

- lowered mental workload and increased situation awareness

In the post-test briefing, the vast majority of EPs (9) preferred that the guidance cue should be retained all the way to flare and not be removed at $\mathrm{DH}$. Interestingly, 3 EPs stated they did not notice guidance cue variations as they were either visual at that point in the approach or using the flight path marker and glide slope reference line to make the landing after turning to the runway.

\section{Concluding Remarks}

An experiment was conducted to investigate the use of SEVS technologies as enabling technologies for future all-weather operations. The experimental objectives were to evaluate head-up SEVS concepts, instrument offset approaches, HUD edge lines positioning sources, and guidance cue variations on crew landing performance and subjective ratings of situation awareness and workload during terminal area operations.

Objective results indicate that flying HUD SEVS concepts on an offset approach had no adverse effects on touchdown performance. All touchdowns occurred within the AWO touchdown box irrespective of the approach offset type (0, 3, 15 deg) or HUD SEVS concept (Conventional, SVS, EFVS) being flown. Subjective assessments of mental workload and situation awareness also indicated that making offset approaches in low visibility conditions with an EFVS HUD or SVS HUD appears feasible.

Guidance cue variation significantly impacted T/D longitudinal position and missed approach rate while conducting an ILS 3-deg offset approach. With the guidance cue latched to the flare cue, $8 \%$ of the runs resulted in a go-around and landings were closer to the aim point with a higher (on average) T/D sink rate. When the guidance cue was removed at DA, there were no missed approaches and the landings were farther past the aim point with a lower T/D sink rate. HUD edge lines positioning source did not affect touchdown performance.

FLIR-based sensor technology used in conjunction with the HUD (i.e., an EFVS) enabled successful no-offset approaches, without any goarounds being performed, in visibility as low as 1000 RVR in this simulation experiment. Future research should investigate enhanced vision sensor technologies (other than FLIR) for improved allweather operations when reported visibility is less than 1000 RVR.

\section{References}

[1] Joint Planning and Development Office, 2008, Next Generation Air Transportation System Integrated Plan: A Functional Outline, Washington, DC.

[2] Federal Aviation Administration, Instrument Flight Procedures (IFP) Inventory Summary, Retrieved February 28, 2011, from 
http://www.faa.gov/air traffic/flight info/aeronav/ifp inventorysummary.

[3] Arthur, J. J., III, L. J., Prinzel III, L. J. Kramer, R. E. Bailey, R. V. Parrish, 2003, CFIT Prevention Using Synthetic Vision, Proceedings of SPIE, Enhanced and Synthetic Vision 2003, 5018, 146-157.

[4] Schiefele, J., D. Howland. J. Maris, C. Pschierer, P. Wipplinger, M. Meuter, 2005, Human Factors Flight Trial Analysis for 3D SVS: Part II, Proceedings of SPIE, Enhanced and Synthetic Vision 2005, 5802, 195-206.

[5] Kramer, L. J., L. J. Prinzel III, R. E. Bailey, , J. J. Arthur III, 2003, Synthetic Vision Enhances Situation Awareness and RNP Capabilities for TerrainChallenged Approaches, Proceedings of the American Institute of Aeronautics and Astronautics Third Aviation Technology, Integration, and Operations Technical Forum, AIAA 2003-6814, 1-11.

[6] Lemos, K., T. Schnell,, 2003, Synthetic Vision Systems: Human Performance Assessment of the Influence of Terrain Density and Texture, Proceedings of 22nd IEEE/AIAA Digital Avionics Systems Conference, 2, pp. 9.E.3 - 91-10.

[7] Schnell T., Y. Kwon, S. Merchant, T. Etherington, T. Vogl, 2004, Improved Flight Technical Performance in Flight Decks Equipped with Synthetic Vision Information System Displays, International Journal of Aviation Psychology, 4, 79-102.

[8] Alexander, A. L., C. D. Wickens, T. J. Hardy, 2005, Synthetic Vision Systems: The Effects of Guidance Symbology, Display Size, and Field Of View, Human Factors: The Journal of the Human Factors and Ergonomics Society, 47 (No. 4), 693-707.

[9] McKenna, Ed, May 2012, Synthetic Vision Systems, Avionics Magazine, Rockville, MD, Access Intelligence, pp. 20-23.

[10] Connor, Glenn, April 2011, On the Road to ZeroZero, Professional Pilot Magazine, Alexandria, VA, Queensmith Communications Corporation, pp. 22-27.

[11] RTCA, December 2008, Minimum Aviation System Performance Standards (MASPS) for Enhanced Vision Systems, Synthetic Vision Systems, Combined Vision Systems and Enhanced Flight Vision Systems, RTCA/DO-315, Washington, DC.

[12] Enhanced Flight Vision Systems, RIN 2120AJ94, Washington DC, DOT/FAA, Retrieved May 1,
2013, from http://www.reginfo.gov/public/do/eAgendaViewRule ?pubId=201210\&RIN=2120-AJ94.

[13] RTCA, September 2010, Minimum Aviation System Performance Standards (MASPS) for Enhanced Vision Systems, Synthetic Vision Systems, Combined Vision Systems and Enhanced Flight Vision Systems, RTCA/DO-315A, Washington, DC.

[14] Bailey, R. E., L. J. Kramer, S. P. Williams, 2010, Enhanced Vision For All-Weather Operations Under NextGen, Proceedings of SPIE Enhanced and Synthetic Vision Conference 2010, 7689, pp. 7689031-768903-18.

[15] Kramer, Lynda J., Randall E. Bailey, Kyle K. E. Ellis, Steven P. Williams, Jarvis J. Arthur III, Lawrence J. Prinzel III, Kevin J. Shelton, 2013, Enhanced Flight Vision Systems and Synthetic Vision Systems for NextGen Approach and Landing Operations, NASA/TP-2013-218054, NASA Langley Research Center, Hampton, VA.

[16] Shelton, K. J., L. J. Kramer, K. K. Ellis, S. A. Rehfeld, 2012, Synthetic and Enhanced Vision Systems for NextGen (SEVS) Simulation and Flight Test Performance Evaluation, Presented at 31st Digital Avionics Systems Conference, October 14-18, 2012, Williamsburg, Virginia.

[17] Corps, S. G., 1986, Airbus A320 Side Stick and Fly By Wire - An Update, 5th SAE Aerospace Behavioral Engineering Technology Conference, Paper No. 861801.

[18] RTCA, March 2011, Minimum Aviation System Performance Standards (MASPS) for Enhanced Vision Systems, Synthetic Vision Systems, Combined Vision Systems and Enhanced Flight Vision Systems, RTCA/DO-315B, Washington, DC.

[19] FAA, October 2009, Global Positioning System Wide Area Augmentation System (WAAS) Performance Standard, Washington, DC.

[20] Ames, Lawrence L., Edward J. George, 1993, Revision and Verification of a Seven-Point Workload Estimation Scale, Air Force Flight Test Center: AFFTC-TIM-93-01.

[21] AIAA, 1993, Guide to Human Performance Measurement, Washington, DC.

[22] Federal Aviation Administration, July 13, 1999, Criteria for Approval of Category III Weather Minima 
for Takeoff, Landing, and Rollout, AC-120-28D, Washington, DC.

[23] European Aviation Safety Agency, February 2007, JAR AWO: All-Weather Operations, Amendment 4, Englewood, Colorado, Global Engineering Documents.

[24] West, Brady T., Kathleen B. Welch, Andrzej T. Galecki, 2007, Linear Mixed Models: A Practical
Guide Using Statistical Software, Boca Raton, FL, Taylor and Francis Group.

33rd Digital Avionics Systems Conference October 5-9, 2014 